\title{
PREDISPOSING FACTORS IN PATIENTS (FROM A RURAL BACKGROUND) PRESENTING WITH LENS INDUCED GLAUCOMA
}

\author{
Gajjala R. Bharath Kumar ${ }^{1}$
}

${ }^{1}$ Assistant Professor, Department of Ophthalmology, Regional Eye Hospital/Kakatiya Medical College, Warangal.

ABSTRACT

\section{BACKGROUND}

The aim of this study was to investigate the various predisposing factors in cases presenting with Lens Induced Glaucoma (LIG).

\section{MATERIALS AND METHODS}

Retrospective study of 126 patients with lens induced glaucoma presented to Govt. Regional Eye Hospital, Warangal. Distance of the patient's residence from Regional Eye Hospital, age, sex, occupation, socioeconomic status, literacy and surgical history of the other eye noted. Visual acuity and intraocular pressure were noted.

\section{Inclusion Criteria}

All admitted and diagnosed cases of lens induced glaucoma.

\section{Exclusion Criteria}

Post-trauma cases with glaucoma and patients residing in villages less than 50 kilometres.

\section{RESULTS}

Out of 126 patients 110 (87.3\%) had other eye operated for cataract, out of which 98 had post-operative best corrected visual acuity more than $6 / 12$ and the remaining 12 had best corrected visual acuity less than $6 / 12$. All 12 patients with best corrected visual acuity less than $6 / 12$ returned for an operation in other eye within one year. Out of 98 patients with good vision (best corrected visual acuity more than 6/12) 18 patients came between $1-3$ years, while other 80 patients came after 3 years. 120 patients (95.2\%) were from villages more than 50 kilometres distance from Govt. Regional Eye Hospital and 6 patients (7.6\%) from villages from less than 50 kilometres. All patients were illiterates. 104 patients were agricultural labourers and 22 were idle at home depending on their family members. 115 patients $(91.2 \%)$ were from low socioeconomic status, 110 patients had other eye operated and 16 patients with immature cortical cataract with $6 / 60$ visual acuity. 74 patients (58.7\%) presented with phacomorphic type of lens induced glaucoma and $52(41.3 \%)$ patients with phacolytic type of lens induced glaucoma.

\section{CONCLUSION}

Majority of the patients with lens induced glaucoma are pseudophakic in other eye (87.3\%). Gross negligence of one eye because of satisfactory vision in other eye, illiteracy, occupational compulsions, poor socioeconomic status, rural background, all play an important role in lens induced glaucoma. Lens induced glaucoma develops when a long standing cataract becomes mature or hypermature. The patients seeking treatment typically had a painful red eye, but careful questioning will usually reveal a long history of decreasing visual acuity.

\section{KEYWORDS}

Lens Induced Glaucoma, Secondary Glaucoma, Pseudophakia.

HOW TO CITE THIS ARTICLE: Kumar GRB. Predisposing factors in patients (from a rural background) presenting with lens induced glaucoma. J. Evolution Med. Dent. Sci. 2016;5(84):6242-6243, DOI: 10.14260/jemds/2016/1411

\section{BACKGROUND}

Lens induced glaucoma was first described in the year 1900 by Gifford and Von Reuss independent of each other. Gifford described it as a glaucoma associated with hypermature cataract. Reuss described it as a glaucoma associated with spontaneous absorption of lens substance through intact lens capsule. Lens induced glaucoma is characterised by secondary glaucoma in one eye with senile mature cataract, senile hypermature cataract, rarely immature senile cataract.

Financial or Other, Competing Interest: None.

Submission 06-09-2016, Peer Review 25-09-2016,

Acceptance 28-09-2016, Published 18-10-2016.

Corresponding Author:

Dr. Gajjala R. Bharath Kumar,

Assistant Professor,

Regional Eye Hospital/Kakatiya Medical College,

Warangal, Telangana.

E-mail:drbhasha@yahoo.com

DOI: $10.14260 /$ jemds/2016/1411
Normal intraocular pressure and open angle in other eye. Lens induced glaucoma remains one of the most important cause of irreversible loss of vision, as most of the patients reporting late.

\section{MATERIALS AND METHODS}

This prospective study included 126 patients with lens induced glaucoma presented to Govt. Regional Eye Hospital, Warangal. These patients diagnosed as lens induced glaucoma on the basis of clinical symptoms and signs. Clinical features included pain, loss of vision, redness of the eye, presence of an intumescent, mature or hypermature cataract associated with raised intraocular pressure of more than $21 \mathrm{mmHg}$. They are from various distances and presented with painful red eye with different duration. Relevant history of patient's sex, age, occupation, literacy, socioeconomic status, distance of their residence from the Govt. Regional Eye Hospital, Warangal and best corrected visual acuity noted. A detailed clinical examination of both eyes included the status of the lens, depth 
of the anterior chamber by slit lamp examination, intraocular pressure recording with Schiotz tonometer, gonioscopy. Based on slit lamp examination, the type of lens induced glaucoma was diagnosed. Phacomorphic glaucoma was diagnosed when patients presented with red eye, severe pain and diminished vision. On clinical examination the eye showed ciliary congestion, corneal oedema, shallow anterior chamber, dilated and fixed pupil, intumescent cataract and intraocular pressure more than $21 \mathrm{mmHg}$. The patients were diagnosed with phacolytic glaucoma when they complained of severe pain and redness in eye with long standing poor vision. On examination the eye showed marked diminished vision, corneal oedema, normal or deep anterior chamber containing liquefied lens particles and pseudohypopyon in severe cases and hypermature Morgagnian cataractous lens in some cases. The parameters noted were age, sex, occupation, educational qualification, socioeconomic status and surgical history of other eye, residing distance from Govt. Regional Eye Hospital. Informed consent was taken from all the patients involved in this study.

\section{Inclusion Criteria}

All admitted diagnosed cases of lens induced glaucoma.

\section{Exclusion Criteria}

Post-trauma cases with glaucoma and patients residing in villages less than 50 kilometres from Regional Eye Hospital.

\section{RESULTS}

This series comprises of 126 patients with lens induced glaucoma. ${ }^{1}$ Out of 126 patients, 120 (95.2\%) were from villages and the distance of those villages from Govt. Regional Eye Hospital is more than 50 kilometers. ${ }^{1}$ Females were 70 (55.6\%) and males were $56(44.4 \%) .^{2}$ All patients were more than 55 years of age. ${ }^{2}$ All patients were illiterates. ${ }^{3} 104$ patients were agricultural labourers and 22 were idle at home depending on their family members. $115(91.2 \% \%)$ patients were from low socioeconomic status. ${ }^{1} 110(87.3 \%)$ patients had other eye operated and $16(12.7 \%)$ patients with immature cortical cataract with $6 / 60$ visual acuity. 74 (58.7\%) patients presented with phacomorphic type of lens induced glaucoma and $52(41.3 \%)$ patients presented with phacolytic type of lens induced glaucoma. ${ }^{1}$

Out of 110 patients with other eye pseudophakia, 98 patients having best corrected visual acuity more than $6 / 12$. 12 patients having best corrected visual acuity between $6 / 18$ and 6/60. 90 patients came to the hospital 3 years after the first eye surgery (All of them have best corrected visual acuity more than $6 / 12$ after surgery). 8 patients came to the hospital within 1-3 years (Best corrected visual acuity between 6/12 to 6/24), 12 patients came to the hospital within one year (best corrected visual acuity between $6 / 36$ to $6 / 60$ ). ${ }^{4}$

\begin{tabular}{|c|c|c|c|}
\hline Sl. No. & Age in Years & No. of Cases & Percentage \\
\hline 1 & $55-60$ & 55 & $43 \%$ \\
\hline 2 & $61-65$ & 30 & $24 \%$ \\
\hline 3 & $66-70$ & 21 & $17 \%$ \\
\hline 44 & 71 and Above & 20 & $16 \%$ \\
\hline \multicolumn{4}{|c|}{ Table 1: Age Incidence } \\
\hline
\end{tabular}

\begin{tabular}{|c|c|c|c|}
\hline Sl. No. & Sex & No. of Cases & Percentage \\
\hline 1 & Male & 56 & $44.4 \%$ \\
\hline 2 & Female & 70 & $55.6 \%$ \\
\hline \multicolumn{3}{|c|}{ Table 2: Sex Incidence } \\
\hline
\end{tabular}

\begin{tabular}{|c|c|c|c|}
\hline Sl. No. & Occupation & No. of Cases & Percentage \\
\hline 1 & $\begin{array}{c}\text { Agricultural } \\
\text { Labourers }\end{array}$ & 104 & $82.5 \%$ \\
\hline 2 & Idle at home & 22 & $17.5 \%$ \\
\hline \multicolumn{3}{|c|}{ Table 3: Occupation } \\
\hline
\end{tabular}

\begin{tabular}{|c|c|c|c|}
\hline $\begin{array}{c}\text { Sl. } \\
\text { No. }\end{array}$ & $\begin{array}{c}\text { Type of Lens } \\
\text { Induced Glaucoma }\end{array}$ & $\begin{array}{c}\text { No. of } \\
\text { Cases }\end{array}$ & Percentage \\
\hline 1 & Phacomorphic type & 74 & $58.7 \%$ \\
\hline 2 & Phacolytic type & 52 & $41.3 \%$ \\
\hline \multicolumn{4}{|c|}{ Table 4: Type of Lens Induced Glaucoma } \\
\hline
\end{tabular}

\begin{tabular}{|c|c|c|c|}
\hline $\begin{array}{c}\text { Sl. } \\
\text { No. }\end{array}$ & $\begin{array}{c}\text { Status of } \\
\text { Other Eye }\end{array}$ & $\begin{array}{c}\text { No. of } \\
\text { Cases }\end{array}$ & Percentage \\
\hline 1 & Pseudophakia & 110 & $87.3 \%$ \\
\hline 2 & $\begin{array}{c}\text { Immature } \\
\text { Cortical Cataract }\end{array}$ & 16 & $12.7 \%$ \\
\hline \multicolumn{4}{|c|}{ Table 5: Status of Other Eye } \\
\hline
\end{tabular}

\begin{tabular}{|c|c|c|c|}
\hline $\begin{array}{c}\text { Sl. } \\
\text { No. }\end{array}$ & $\begin{array}{c}\text { Distance in } \\
\text { Kilometres }\end{array}$ & $\begin{array}{c}\text { No. of } \\
\text { Cases }\end{array}$ & Percentage \\
\hline 1 & Less than 50 & 6 & $5 \%$ \\
\hline 2 & $51-60$ & 74 & $59 \%$ \\
\hline 2 & $61-70$ & 8 & $6 \%$ \\
\hline 4 & More than 70 & 38 & $30 \%$ \\
\hline \multicolumn{4}{|c|}{ Table 6: Residing Distance from Hospital } \\
\hline
\end{tabular}

\section{DISCUSSION}

The purpose of this study is to enlighten the factors that are influencing the lens induced glaucoma in rural population, as majority of patients are belonging to low socioeconomic groups. Most of these patients are having reasonable good vision in operated eye and which is sufficient for their daily work and day-to-day life. As they are having reasonable good vision in one eye, they are neglecting the other eye by themselves or neglected by the family members years together till they land up in lens induced glaucoma. Distance from the hospital and illiteracy are also contributing factors for their negligence. Most of the patients in this study were having pseudophakia in other eye. We can prevent the incidence of lens induced glaucoma by educating the patient when we are doing cataract surgery in first eye itself or educating them at village level by regular eye checkups by conducting eye camps and with the help of paramedical staff at primary health centre level.

\section{REFERENCES}

1. Pradhan D, Henning A, Kumar J, et al. A prospective study of 413 cases of lens-induced glaucoma in Nepal. Indian J Ophthalmol 2001;49(2):103-7.

2. Prajna N, Ramakrishna R, Krishnadas $R$, et al. Lens induced glaucoma-visual results and risk factors for final visual acuity. Indian J Ophthalmol 1996;44(3):149-55.

3. Snellingen T, Shrestha BR, Gharti MP, et al. Socioeconomic barriers to cataract surgery in Nepal: the south Asian cataract management study. $\mathrm{Br} \mathrm{J}$ Ophthalmol 1998;82(12):1424-8.

4. Lim T, Tan D, Fu E. Advanced cataract in Singapore-its prognosis and complications. Ana Acad of Med 1993;22(6):891-94. 